\title{
Introduction to Healthy Minds: Mental Health Practice and Perception in the Twentieth Century
}

\author{
Steven J. Taylor and Alice Brumby
}

\section{INTRODUCTION}

Writing in the 1980s, Peter Barham noted that in 1985 the average number of psychiatric beds occupied each day in England and Wales was 64,800 , a return to the occupancy level last witnessed in $1895^{\prime} .{ }^{1}$ In a local case study of the Exeter region, the number of inpatient beds in mental hospitals had fallen from 2070 in the middle of the twentieth century (1949) to only 100 beds in 1996. Ten years later, this number had dropped again to only 40 beds. ${ }^{2}$ Similar figures can be found for different regions across the UK. ${ }^{3}$ This reduction of provision in the country's mental hospitals and the narrative of deinstitutionalisation

\section{S. J. Taylor $(\bowtie)$ \\ School of History, University of Leicester, Leicester, UK e-mail: sjt48@leicester.ac.uk}
A. Brumby
School of Humanities, Religion \& Philosophy, York St John University, York, UK
e-mail: a.brumby@yorksj.ac.uk
(C) The Author(s) 2020
S. J. Taylor and A. Brumby (eds.), Healthy Minds
in the Twentieth Century, Mental Health in Historical Perspective, https://doi.org/10.1007/978-3-030-27275-3_1 
communicates only a part of the history of mental health care over the course of the twentieth century. ${ }^{4}$ While there was a sea change from institutional to social care in the provision and treatment of mental health, there was also a move beyond metaphorical walls that saw concerns about mental health penetrate previously untouched aspects of everyday life. The contributions to this book are an attempt at providing historical context to this change, as well as revealing some of the new physical and cultural spaces that mental health now occupies.

In economic, military, medical and social arenas, the twentieth century was one of change and development. As the century progressed, advances in surgery and medicine meant that people were living into older age, while, on the other hand, political and military situations demonstrated a prolificacy in destroying human life. The early decades of the century also saw a re-emphasis on the importance of the individual, their place in society and, alongside this, their health and well-being. Individuals were now tasked with an expectation of social efficiency that meant providing for themselves and their families but also, in their own way, contributing to the national project-whether through work, service or reproducing healthy stock. In this climate, minds considered to be 'unhealthy' were represented as a unique threat and took on a particular status that combined concern with stigma. From the degenerative worries of eugenic discourse through to the stresses and strains of modern living in the late-twentieth century, there was ever more awareness on preserving 'healthy' minds. Consequently, medical practices of removing the 'insane' from society and confining them in specialist institutions largely subsided and increased scientific, medical and sociocultural investment led to better understanding of conditions such as epilepsy, 'shell shock' and depression, as well as the emergence of new conditions such as schizophrenia, autism and post-traumatic stress disorder.

Throughout this volume, the terms 'healthy' and 'unhealthy' have no fixed meaning and are deployed subjectively in relation to the mental health of individuals and groups. The definitions have subsequently been determined by contributing authors in relation to a range of factors such as time, place and space. On the whole, the healthy/unhealthy dichotomy aims to identify instances where mental health was demarcated from what was considered socially, medically, culturally or legally 'normal'. Therefore, there is no single example of a healthy mind nor is there one of an unhealthy mind. To complicate the situation further, 
it might be that a mind might be considered unhealthy in some scenarios, and yet not in others. An example is that of learning disabilities; in Chapter 5, Jan Walmsley discusses some of the negative connotations and stigma attached to such conditions. Yet, in Chapter 8, authored by Dyck and Russell, the passage of time and changing cultural landscape of the twentieth century had shaped the experience of living with learning disability into something considered to be healthier, or socially accepted with the coming of the neurodiversity movement.

As the shifting understanding of what was considered to be a healthy mind suggests, and the chapters that follow will attest, the nomenclature of mental health was fluid and contested throughout the twentieth century. Thus, it is worth observing at the outset some of the terminologies that will feature. At the beginning of the twentieth century, the medical lexicon of mental health included terms such as 'lunatic', 'imbecile' and 'idiot' that all fell under the catch-all umbrella of 'insanity'. By the time that the century had ended, all of these medical terms had taken on derogatory connotations and were laced with stigma. The fate of these labels was not unique and the twentieth century saw language of its own-'feeble-minded', 'schiz' and 'cretin' related to mental health that fell into wider, negative, social use. As these terms feature in the academic analysis of this volume, it is worth observing that they are used by authors to demonstrate their arguments and with no malice or negativity in mind. Instead, terminology is used to reflect the historical nomenclature of the time period discussed.

The evolving language of mental health over the course of the twentieth century also reflects a widening social awareness of mental illness and disability. It was within this context that psychiatrists and medical experts became increasingly concerned with preventative mental health care, or the need to keep minds healthy. This fascination was the impetus behind a range of twentieth-century innovations, from charitable bodies to government policies, and societal doctrines. The preoccupation with maintaining and perpetuating healthy minds informed Eugenic discourse, the neo-hygienist child guidance movement, psychiatric social work and a host of legislation passed during the twentieth century-from the Mental Deficiency Act, 1913, to the policy of transition from treatment in mental hospitals to care in the community in the latter-half of the twentieth century. Nineteenth-century alienists, working in the field of mental health, often argued that late admittance to the asylum, and with it delayed treatment, led to the 
growing population of hopeless chronic cases, who languished in the institution uncured until their deaths. ${ }^{5}$ In the twentieth century, there was a move away from cure, amelioration and modification, and the contributions to this volume from Dyck and Russell, Walmsley, and O'Reilly et al. reveal an advocacy and shared-identity towards mental health that would have been unimaginable a century before.

\section{Places of Care for the 'Unhealthy' Mind}

By the early to mid-twentieth century, overcrowding in asylums had highlighted, what appeared to be, the failure of institutionalisation. Subsequently, a range of other options emerged that attempted to ease pressure on over-crowded Victorian institutions. ${ }^{6}$ To many, the late-nineteenth century symbolised a time of pessimism and decline in psychiatric services. ${ }^{7}$ The argument that an increase in uncured chronic patients at the end of the nineteenth and early-twentieth centuries symbolised a period of stagnation within the walls of the asylum has been popularised by Andrew Scull. ${ }^{8}$ Such a view has found traction in the literature, and Peter Bartlett stated that 'historians tend to view the asylum in the later-nineteenth century as a failure, full of incurable cases and unable to fulfil the humanitarian promise of the reformers'. ${ }^{2}$ Echoing this perspective, Melling and Forsythe argued that the asylum model had 'exhausted its potential for innovation' long before $1890 .{ }^{10}$ The growing demands upon care and the medical inability to cure the chronically ill are not disputed within this volume, nor is the idea that this growing 'underclass' of chronic patients can be seen, at some levels, to represent a failure in psychiatry at this time. Despite this, however, not all psychiatrists were negative and they saw ample reason for optimism in the range of new spaces for care in the twentieth century. ${ }^{11}$ It is in these nascent spaces of treatment such as dedicated epilepsy services, special schools, sheltered employment, and patient and caregiver advocacy groups that contributions to this volume focus on.

Many of these newly emerging spaces were promoted and packaged as vehicles for reforming the field of psychiatry, which remained a contentious issue throughout the twentieth century. Critics writing in the second half of the twentieth century highlighted the regulatory nature of traditional asylums, branding them as being 'total institutions'. ${ }^{12}$ Revisionist histories of asylum expansion in the late-nineteenth and earlytwentieth centuries have tended to focus on issues of power and social 
control exerted by medical professionals over their patients. ${ }^{13}$ These accounts modified older interpretations, which highlighted a humanitarian narrative focusing on psychiatry's progressive nature. ${ }^{14}$ Critics argued that to focus solely on the humanitarian objectives of psychiatry was nothing more than an effort to legitimise and historicise the profession. ${ }^{15}$ Arguably, creating new spaces of treatment and cure was an attempt not only to legitimise the psychiatric profession, but also to influence the (de)stigmatisation of mental illness across the long twentieth century. ${ }^{16}$

Despite the lingering images of mental institutions in the cultural imagination, historians have shown that the locus of care and treatment for those with mental health issues was never limited to the pauper lunatic asylum and, even in the nineteenth century, the economy of care sprawled across a range of settings in which the healthy and unhealthy mind could be presented, contested and represented. ${ }^{17}$ These spaces and places included familial homes, boarding out with foster families, early mental health clinics, general hospitals and workhouse wards to name but the most popular. ${ }^{18}$ Historians have come to accept that institutions were not closed, medicalised dumping grounds, but instead were porous, contingent and occasionally even temporary spaces where patients, staff, families and other stakeholders interacted. ${ }^{19}$ Scholars have meticulously begun to show how the walls of the asylum were more permeable than our previous understanding suggests. ${ }^{20}$ It is within the pluralistic landscape of care that this volume positions itself in an attempt to better understand the diverse physical and conceptual spaces that mental health came to penetrate in the twentieth century. In accordance with this broad and ambitious approach, the contributions to this volume span academic fields such as history, arts, literary studies, sociology and psychology, mirroring the diversity of the subject matter.

Healthy Minds, as a volume, contributes a new dimension to the study of mental health and psychiatry in the twentieth century. It takes the present literature beyond the 'asylum and after' paradigm to explore the multitude of spaces that have been permeated by concerns about mental well-being and illness. Unlike previous studies, the chapters in this volume consciously attempt to break down institutional walls and consider mental health through the lenses of institutions, policy, nomenclature, art, lived experience and popular culture. It also adopts a broad international scope covering the historical experiences of Britain, Ireland and North America. 


\section{Mental Health in the Twentieth Century: Policy and Practice}

The Mental Deficiency Act, 1913, signalled a continuation of the nineteenth-century obsession with classifying and segregating individuals according to their mental health. ${ }^{21}$ This legislation, dealing with so-called mental defectives, emphasised the dangers posed to society by those who previously might not have been the focus of medical experts. Subsequently, the new legal category of the 'feeble-minded' provided a label for individuals considered less severely disabled than 'idiots' and 'imbeciles', but 'weak-minded' enough to be more susceptible to crime, promiscuity and idleness. ${ }^{22}$ Furthermore, the Act also established the Board of Control as a national body with overview of local authorities and their running of 'mental deficiency' services. Contributions to this volume by Jan Walmsley and Steve Taylor explore the impact of labelling and the consequences for individuals that this legislation targeted in more depth, both demonstrating the significance and lasting impact of its scope. Despite the eugenic appeal of this legislation, the pace of implementation was hampered by the First World War, restricted finances resulting from this conflict and the oncoming depression.

The Great War led to a crisis in the asylums of England and Wales as 27,778 permanent civilian beds were cleared and loaned to the Military Authorities to cater for injured personnel. ${ }^{23}$ The result was devastating overcrowding in the remaining hospitals and a massive upsurge in asylum deaths. ${ }^{24}$ Despite medical officers' best attempts, the 1920 s continued to see an ever-increasing rise in the numbers of patients institutionalised. ${ }^{25}$ It has been widely argued that the predominance of soldiers breaking down on the front led to some changes in the public view of mental illness. ${ }^{26}$ However, the apparent inability of medical professionals to cure these men meant that any changes in attitudes were short-lived. ${ }^{27}$ By the late 1920s, unrecovered 'shell-shocked' ex-servicemen found themselves languishing in asylums often alongside the chronically ill civilian population. ${ }^{28}$

By the time that the Mental Treatment Act, 1930, was passed, overcrowding in the nation's institutions for mental health had reached dire proportions. ${ }^{29}$ Demand on services was so severe that hospital treatment was not always possible, and as such, patients often did not receive treatment until they reached an incurable stage of their illnesses. ${ }^{30}$ The Mental Treatment Act, 1930, sought to prioritise early treatment 
by setting up categories of mental health care, which could bypass the lengthy certification process associated with previous experience. The act made provision for temporary and voluntary patients to be admitted to a mental hospital without the need for certification. ${ }^{31}$ Importantly, it also championed the use of outpatient clinics and changed the name of the institution from an 'asylum' to a 'mental hospital' and reclassified 'pauper lunatics' to 'rate-aided' patients'. The change in nomenclature was clearly an attempt to remove the stigma from mental illness. ${ }^{32}$

Despite the hopes of the Mental Treatment Act, the Board of Control's desire to see mental health services reach parity with physical health did not occur properly until the founding of the National Health Service (NHS) in 1948. Even after services were officially aligned, mental health continued to remain the 'poor and embarrassing relative' of physical health in the popular imagination. ${ }^{33}$ The Mental Health Act, 1959, attempted to alter this perception by repealing previous legislation relating to the Lunacy, Mental Treatment and Mental Deficiency Acts. By doing so, the distinction between psychiatric and other hospitals was fully removed. ${ }^{34}$ However, the 1959 mental health legislation continued to justify compulsory detention for patients 'who may not know they are ill' and therefore may be unwilling to undergo treatment. ${ }^{35}$ It was not until the Mental Health Act, 1983, where the ideas of consent were fully considered. Prior to this, in 1962, Enoch Powell produced his Hospital Plan for England and Wales, formally promoting the government's desire to dramatically reduce the number of inpatient mental hospital beds, and close down the hospitals by the end of the twentieth century. Of the 130 psychiatric hospitals in England and Wales in 1975, by 2005 only 14 remained open. ${ }^{36}$

Coinciding with a move towards non-institutional care in the 1960s was the emergence of the influential and popular anti-psychiatry movement. ${ }^{37}$ In 1961, Thomas Szasz in his book The Myth of Mental Illness argued against the forcible detention of those who, he suggested, merely deviated from established societal norms. ${ }^{38}$ Similarly, scholars such as Erving Goffman, Gilles Deleuze and Felix Guattari offered critiques of psychiatry's social influence and power and objected to the use of models and terms, inclusive of 'total institutions' that served to 'other' elements of the population. ${ }^{39}$ Perhaps most famously, Michel Foucault in his seminal work Histoire de la Folie charted how attitudes towards the insane shifted with changing social values. He argued that psychiatry functioned as a tool of social control that began with 
a state-sponsored 'Great Confinement' of deviant populations. ${ }^{40}$ Deinstitutionalisation evidently occurred at a time when arguments against psychiatry, and its social purpose, were gathering traction with more effective popular media vehicles.

Yet, while the closing of hospitals and focus on care in the community might sound unprecedented, it really was unique in size and scale alone. The move towards extramural forms of care was not exclusive to the mid-twentieth century, with outpatient departments available to those who did not require inpatient care pioneered as early as the 1890s. ${ }^{41}$ Throughout this plotted history, we can see a desire to maintain the healthy mind, by classification and control, early treatment and the attempted removal of stigma, by endeavouring to bring mental health services in line with physical health. Whatever the legislation, there was an increasing focus on maintaining healthy minds and in doing so, maintaining a healthy society. If Bartlett and Wright's volume taught us that 'the boundaries between the asylum and the community are vague and uncertain', ${ }^{42}$ then this volume identifies that throughout the twentieth century the boundaries between illness and wellness and the unhealthy and healthy mind can be similarly contested.

\section{Keeping Minds Healthy: About the Chapters}

Recent work has identified the importance of preventing mental illness and identifying its potential triggers, with Despo Kritsotaki et al. observing the modern nature of this particular focus. ${ }^{43}$ In part, this volume seeks to answer the call for more research into this area, as the twentieth-century concentration on the healthy mind fits within this wider agenda of improved well-being and preventative mental health care. The objective of this book is to explore, what might be described as, the sprawl of mental health over the course of the twentieth century. This might be inelegant language, but there is a focus in the twenty-first century, at least in the Western world, on making sure that we are doing our best to keep our minds healthy. Cases in point are present-day concerns about the amount of time children, and adults, spend looking at digital screens; the negative effects of social media on everyday lives; anxieties about the body and self-image; and the consequences of substance abuse, particularly the emergence of synthetic drugs that are affordable and readily available. The contributions to this volume adopt an historical lens to help understand this present preoccupation with the healthy 
mind. Such an approach has meant that author contributions feature a diverse range of content, from traditional pauper lunatic asylums through to popular visual culture. Nevertheless, three broad themes, amongst others, emerge across the chapters that follow.

The first of these is the legal and medical classification of mental illness and disability, which has been a recurrent theme in the literature. At the beginning of the twentieth century, psychiatrists were fascinated with the distinction between mental health and learning disability, increasingly finding new ways of classifying those that they described as mentally defective and developing various gradations of the condition. The solutions that emerged to this supposed social problem were segregation of the afflicted, from society, as well as other populations of the insane, in order to create new physical spaces for their education and treatment. ${ }^{44}$ Chapters by Steve Taylor and Jan Walmsley focus heavily on these emerging classifications and their significance. Walmsley, in particular, identifies the importance of labelling from a social perspective, while demonstrating the fluidity of language and the unintended legacies of medical classification.

With the publication of the Diagnostic and Statistical Manual of Mental Disorders (DSM) in 1968, and its subsequent iterations, psychiatrists were buoyed by an international classificatory system that was grounded in science and data. The contributions from Erika Dyck and Ginny Russell, Michelle O'Reilly et al. and Alice Brumby all explore how the new medical confidence in classification affected perception, stigma, treatment and lived experience of learning disability, autism and schizophrenia throughout the twentieth century. O'Reilly et al. discuss the evolution of autism, or as it has been described the "twentieth-century disorder'. Their chapter highlights contested definitions, the challenges of applying labels to spectral disorders and the fractured nature of lived experience for those identifying as 'autistic'. Building on this, the chapter from Dyck and Russell examines how, in some circumstances, the identities created by medical classification fed into disability rights activism and the emergence of the Neurodiversity Movement (NDM) in the second half of the twentieth century. The growth of the NDM represented a complex relationship with medical labels, often appropriating medical languages such as 'patient', 'mad' and 'autistic' and redefining meanings to meet the specific needs of individuals at certain times and places. The nature of identity and experience is developed further in Alice Brumby's chapter. This contribution explores the growth of a relative's support 
organisation, which became the National Schizophrenia Fellowship, established in the 1970s. It aimed to meet the support needs of relatives and families by providing coping strategies that covered a variety of issues, ranging from stigma to caring for a family member. The use of oral history and archival material enables this chapter to argue that the friendship and support networks established by the Fellowship were an important way of dealing with the illness in the 'healthy minds' of non-schizophrenic relatives and caregivers.

The second theme that emerges is the plethora of places and spaces occupied by those living with unhealthy minds. These were mostly conceived by professionals or other stakeholders in a belief that they would be well-suited to treating or observing mental illness or disability. The volume opens with Alice Mauger's discussion of alcohol addiction in Ireland and the treatment of inebriates inside three institutions for lunatics. This chapter charts debates about alcohol-related lunacy and how it was best treated in a climate of nationalism and religion, and it particularly draws out the complicated relationship between alcoholism and the medical community's role in treating it. Moving outside of asylum walls, Rachel Hewitt considers diversifying institutional approaches to epilepsy treatment through an examination of specialist services in Britain and the USA between 1905 and 1965. She observes the similarities between epileptic colonies and open-air schools, marking a departure from asylum treatment and confinement for this class of patient. In these new spaces of well-being, walls were permeable, admission voluntary and treatment designed to improve the whole self. The colonies were about providing stigma-free employment and maintaining the healthy mind in spite of illness. This relationship between employment and the healthiness of the mind recurs in a number of chapters. Steve Taylor's chapter highlights how special education emerged at the beginning of the twentieth century as a mechanism for classifying and filtering those who could maintain independent lives from those that could not. In essence, state-sponsored education functioned as a measure of surveillance that sought to establish a healthy workforce while preventing the reproduction of unhealthy families. Moving later into the twentieth century, maintaining stigma-free employment in a safe space, despite an individual's disability, is central to the contribution from Andy Holroyde. Remploy was established in the UK in 1944 as part of the provision of the Disabled Persons Employment Act. It operated as a governmentfunded organisation that provided sheltered employment schemes for 
the disabled. Although it has been assumed that Remploy was originally for those of sound mind, Holroyde's chapter suggests that those with mental disabilities always had a role in the sheltered employment scheme. Allowing the mentally ill access to these services became increasingly important during the 1980 s, to meet the need to provide care services, as an ever-increasing number of psychiatric institutions were closed down. Subsequently, sheltered employment became an important space in which healthy minds were promoted.

The final two chapters in the volume, from Imogen Wiltshire and Rob Mayo, link the theme of space with that of treatment. They focus on art, literature and film, as an important source of healing and well-being, and showcasing how the healthy mind has been represented and contested in the arts. Looking at a range of artistic and cultural practices, Wiltshire's contribution argues that these artistic movements were often at the centre of defining and creating healthy minds. The chapter identifies that in the first half of the twentieth century, the practice of viewing, making and creating art was associated with mental well-being. With a discussion that stretches from Surrealism to occupational and art therapy, the chapter illuminates a variety of historical relationships between art and mental health care. Moving into the world of popular science fiction in the latter half of the twentieth century, Rob Mayo's work focuses on inner space and dream-hacking as an important and influential sub-genre that focused upon the inner workings of the mind. The texts and films featured in Chapter 11 present popular twentieth-century understandings of how the mind works, the damage it can sustain and how it might be fixed. Many of the texts identify a hierarchy between the unhealthy mind and the healthy mind attempting to understand it. Echoing other chapters in the volume, the spaces that feature in the texts include a variety of locations, from the walls of a traditional abandoned asylum to noninstitutional or non-psychiatric spaces.

\section{Conclusions}

Collectively the contributions to this volume look at a plurality of domains, spaces and places in which healthy and unhealthy minds have been represented, dissected and treated throughout the twentieth century. As the twenty-first century develops and a raft of new records becomes available, the twentieth century will become even more fruitful to historians. Perhaps the accessibility of sources has led to the 
dominance of studies into eighteenth- and nineteenth-century, predominantly institutional, mental health care. Historically, the rules on confidentiality and the destruction of records make twentieth-century records more difficult to access than nineteenth-century counterparts. ${ }^{45}$ Despite this, however, research into twentieth-century institutions and loci of care are becoming more frequent within the historiography. Focusing on the twentieth century, and building on the work of Bartlett and Wright's influential edited collection Outside the Walls of the Asylum, this volume aims to look beyond the walls of psychiatric institutions. Certainly, throughout the twentieth century, health care professionals and policymakers have broadened and diversified the role of mental health care and opened up new spheres and centres for creating healthy minds. From the opening of child guidance and outpatient clinics to experiments with drugs, the twentieth century created new ways of policing and assessing the mind. This volume seeks to shed new light on these practices and centres which aimed to maintain the healthy minds of the collective and individual in a transnational context.

\section{Notes}

1. Peter Barham, Closing the Asylum: The Mental Patient in Modern Society (London: Penguin Books, 1992), 17.

2. A. Know and C. Gardner-Thorpe, The Royal Devon and Exeter Hospital 1741-2006 (Exeter: Knox and Garner-Thorpe, 2008), 90-98.

3. Dylan Tomlinson, Utopia, Community Care and the Retreat from the Asylums (Buckingham: Open University Press, 1991), 42-66.

4. Nick Crossley, Contesting Psychiatry: Social Movements in Mental Health (London and New York: Routledge, 2006).

5. P. W. MacDonald, "Presidential Address on the Early Symptoms of Mental Disease and the Prevention of Insanity," The British Medical Journal 2 (October 1892): 885-887, 885.

6. Edward Hare, "Was Insanity on the Increase?" British Journal of Psychiatry 142, no. I (1983): 439-455; Andrew Scull, "Was Insanity Increasing? A Response to Edward Hare," British Journal of Psychiatry 144, no. 4 (1984): 432-436.

7. Sarah York, "Suicide, Lunacy and the Asylum in Nineteenth Century England" (Unpublished PhD thesis, The University of Birmingham, 2009), 35.

8. Andrew Scull, The Most Solitary of Afflictions: Madness and Society in Britain, 1700-1900 (New Haven and London: Yale University Press, 1993), 271-272. 
9. Peter Bartlett, "The Asylum and the Poor Law," in Insanity, Institutions and Society: A Social History of Madness in Comparative Perspective, eds. Joseph Melling and Bill Forsythe (London: Routledge, 1999), 48-67, 48.

10. Joseph Melling and Bill Forsythe, The Politics of Madness: The State, Insanity and Society in England, 1845-1914 (London: Routledge, 2006), 6.

11. See Fredrick Lyman-Hills, "Psychiatry: Ancient, Medieval and Modern," Popular Science Monthly 60, no. 1 (1901): 31-48. See also Frank Crompton, "Needs and Desires in the Care of Pauper Lunatics: Admissions to Worcester Asylum, 1852-72," in Mental Illness and Learning Disability Since 1850: Finding a Place for Mental Disorder in the United Kingdom, eds. Pamela Dale and Joseph Melling (Oxon: Routledge, 2006), 46-64.

12. Michael Ignatieff, "Total Institutions and Working Classes: A Review Essay," History Workshop Journal 15, no. 1 (March 1983): 167-168.

13. Michel Foucault, Madness and Civilisation: A History of Insanity in the Age of Reason (London: Routledge, 1992); Erving Goffman, Asylums: Essays on the Social Situation of Mental Patients and Other Inmates (Harmondsworth: Penguin, 1986); Andrew Scull, Museums of Madness (London: Allen Lane, 1979).

14. Kathleen Jones, A History of Mental Health Services (London: Routledge and Keegan Paul, 1972); Richard Hunter and Ida Macalpine, Psychiatry for the Poor: 1851 Colney Hatch Asylum-Friern Hospital 1973 (London: Dawsons Pall Mall, 1974).

15. Scull, The Most Solitary of Afflictions, 3.

16. Vicky Long, Destigmatising Mental Illness? Professional Politics and Public Education in Britain, 1870-1970 (Manchester: Manchester University Press, 2014).

17. Peregrine Horden and Richard Smith, eds., The Locus of Care: Families, Communities, Institutions and the Provision of Welfare Since Antiquity (London: Routledge, 1998); Steven J. Taylor, Child Insanity in England, 1845-1907 (Basingstoke: Palgrave Macmillan, 2017).

18. Peter Bartlett and David Wright, "Community Care and its Antecedents," in Outside the Walls of the Asylum: The History of Care in the Community 1750-2000, eds. Peter Bartlett and David Wright (London: The Athlone Press, 1999), 1-18.

19. Louise Wannell, "Patient's Relatives and Psychiatric Doctors: Letter Writing in the York Retreat, 1875-1910," Social History of Medicine 20, no. 2 (July 2007): 297-313; John K. Walton, "Casting Out and Bringing Back in Victorian England, Pauper Lunatics, 1840-70," in The Anatomy of Madness: Essays in the History of Psychiatry, eds. W. F. Bynum, R. Porter, and M. Shepherd (London: Tavistock, 1985), 132-146; David Wright, "Getting Out of the Asylum: Understanding the Confinement of 
the Insane in the Nineteenth Century," Social History of Medicine 10, no. 1 (April 1997): 137-155; David Wright, Mental Disability in Victorian England: The Earlswood Asylum, 1847-1901 (Oxford: Oxford University Press, 2001); Taylor, Child Insanity in England; Steven J. Taylor, “'She Was Frightened While Pregnant By a Monkey at the Zoo': Constructing the Mentally-Imperfect Child in Nineteenth-Century England," Social History of Medicine 30, no. 4 (November 2017): 748-766.

20. Graham Mooney and Jonathan Reinarz, eds., Permeable Walls: Historical Perspectives on Hospital and Asylum Visiting (New York: Rodopi, 2009). See also Bartlett and Wright, "Community Care and its Antecedents," 3.

21. Matthew Thomson, The Problem of Mental Deficiency: Eugenics, Democracy and Social Policy in Britain, c.1870-1959 (Oxford: Oxford University Press, 2001). See also, David King, In the Name of Liberalism: Illiberal Social Policy in the United States and Britain (Oxford, Oxford University Press, 1999).

22. David Wright and Anne Digby, eds., From Idiocy to Mental Deficiency: Historical Perspectives on People with Learning Disabilities (London: Routledge, 1996); Mark Jackson, The Borderland of Imbecility: Medicine, Society, and the Fabrication of the Feeble Mind in Late Victorian and Edwardian England (Manchester: Manchester University Press, 2000).

23. Marriott Cooke and Hubert Bond, History of the Asylum War Hospitals in England and Wales (London: His Majesty's Stationary Office, 1920), 1.

24. John L. Crammer, "Extraordinary Deaths of Asylum Inpatients During the 1914-1918 War," Medical History 36, no. 4 (1992): 430-441.

25. For an illustration of the rise in numbers, see Scull, The Most Solitary of Afflictions, 369.

26. Elaine Showalter, The Female Malady: Women, Madness and the English Culture, 1830-1980 (London: Virago Press, 1996); George Mosse, "Shell Shock as a Social Disease," Journal of Contemporary History 35, no. 1 (January 2000): 101-108, 101; Tracey Loughran, "A Crisis of Masculinity? Re-writing the History of Shell-Shock and Gender in First World War Britain," History Compass 11, no. 9 (2001): 727-738; Ben Shephard, A War of Nerves: Soldiers and Psychiatrists in the Twentieth Century (London: Pimlico, 2002).

27. Peter Barham, Forgotten Lunatics of the Great War (London: Yale University Press, 2007); Fiona Reid, Broken Men: Shell Shock, Treatment and Recovery in Britain, 1914-1930 (London: Continuum, 2011).

28. Alice Brumby, “A Painful and Disagreeable Position’: Rediscovering Patient Narratives and Evaluating the Difference Between Policy and Experience for Institutionalised Veterans with Mental Disabilities, 19241931," First World War Studies 6, no. 1 (June 2015): 37-55. 
29. West Yorkshire Archive Service (Henceforth WYAS), C85/1/6/10, Conference on Mental Hospital Accommodation (1931).

30. WYAS, C85/1/15/13, Annual Reports of the Board of Control (1929), 2.

31. The National Archives (Henceforth TNA), FD 1/1398, Copy of the Mental Treatment Act (1930).

32. Anon., "Mental Treatment: Improvements Under the New Act," The Manchester Guardian, 11 October 1930, 8. See also Alice Brumby, "From Pauper Lunatics to Rate Aided Patients: Removing the Stigma of Mental Health Care 1888-1938" (Unpublished PhD thesis, University of Huddersfield, 2015).

33. Mick Carpenter, "Forward: The Struggle Is Never Over," in Mental Health Nursing: The Working Lives of Paid Carers in the Nineteenth and Twentieth Centuries, eds. Anne Borsay and Pamela Dale (Manchester: Manchester University Press, 2015), xi.

34. Jed Boardman, "New Services for Old: An Overview of Mental Health Policy," in Beyond the Water Towers: The Unfinished Revolution in Mental Health Services 1985-2005, eds. Andy Bell and Peter Lindley (London: The Sainsbury Centre For Mental Health, 2005), 27-36.

35. Barham, Closing the Asylum, 131.

36. Lesly Warner, "Acute Care in Crisis," in Beyond the Water Towers, 38.

37. Nick Crossley, Contesting Psychiatry: Social Movements in Mental Health (London and New York: Routledge, 2006).

38. Thomas Szasz, The Myth of Mental Illness: Foundations of a Theory of Personal Conduct (New York: Harper \& Row, 1961).

39. Erving Goffman, Asylums: Essays on the Social Situation of Mental Patients and Other Inmates (London: Aldine, 2007; originally published [New York: Anchor Books, 1961]); Gilles Deleuze and Felix Guattari, AntiOedipus: Capitalism and Schizophrenia (London: Athlone, 1984; first published Capitalisme er Schizophrenie [Paris: Les Editions de Minuit, 1972]).

40. Michel Foucault, Madness and Civilisation: A History of Insanity in the Age of Reason (London: Routledge, 2001; first published Histoire de la Folie [Paris: Plon, 1961]).

41. Anon., "Bethlem Royal Hospital by a Neurologist," The Times, 7 September 1888, 4; Louise Westwood, "A Quiet Revolution in Brighton: Dr. Helen Boyle's Pioneering Approach to Mental Health Care, 18991939," Social History of Medicine 14, no. 3 (2001): 439-457.

42. Bartlett and Wright, "Community Care," 12.

43. Despo Kritsotaki, Vicky Long, and Matthew Smith, eds., Preventing Mental Illness: Past, Present and Future (Basingstoke: Palgrave Macmillan, 2019). 
44. See for instance, Thomson, The Problem of Mental Deficiency; Mark Jackson, The Borderland of Imbecility; Wright and Digby, From Idiocy to Mental Deficiency.

45. Westwood, "A Quiet Revolution in Brighton," 439-457.

Open Access This chapter is licensed under the terms of the Creative Commons Attribution 4.0 International License (http://creativecommons.org/licenses/ by $/ 4.0 /$ ), which permits use, sharing, adaptation, distribution and reproduction in any medium or format, as long as you give appropriate credit to the original author(s) and the source, provide a link to the Creative Commons license and indicate if changes were made.

The images or other third party material in this chapter are included in the chapter's Creative Commons license, unless indicated otherwise in a credit line to the material. If material is not included in the chapter's Creative Commons license and your intended use is not permitted by statutory regulation or exceeds the permitted use, you will need to obtain permission directly from the copyright holder.

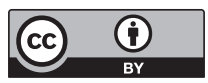

